\title{
Determination of Suitable Areas for Establishment of Sports-City in Iraq's Center Using an Integrated Fuzzy Logic Algorithm and Geomatic Techniques
}

\author{
Haidar R. Mohammed* \\ Civil Engineering Department, University of Technology, Baghdad, Iraq. \\ *Corresponding author Email: 10960@uotechnology.edu.iq
}

\section{H I G H L I G H T S}

\begin{abstract}
- A fuzzy logic algorithm and spatial analysis methods are presented to propose suitable locations for a sports city in Iraq.

- GIS overlay analysis has been applied based on the fuzzy logic algorithm and data input extracted from the spatial analysis process.

- The proposed methodology has combined an intelligence multi-criteria analysis and GIS modelling to support the process of decision making.
\end{abstract}

\section{A R T I C L E I N F O}

Handling editor: Wasan I. Khalil

\section{Keywords: \\ GIS}

Fuzzy logic

Suitability analysis

Sports-city

\section{A B S T R A C T}

In recent times, many cities have clustered new sports infrastructures in concentrated areas to create a sports city. Al Hillah City as one of the biggest cities in the center of Iraq, because of many components' countryside relocation and natural expansion of population, and other has been distinguished; extreme population expansion and lastly evolution in need of planning in some inner-city areas and places. Consequently, designated areas in terms of premier spatial allocation and appropriate location for users of general services; sports services that are rapid, on time, and at ease access to them are essential that are not considered. A small- scale recognition has spent on critical aspects of sports utilization for land measure and appropriately locating. This issue has been minimized the premier performance of these spaces and creates problems for the city and its citizens. The premier performance of these spaces has been minimized because of the above-mentioned issue, which creates difficulties for the city and its residents. This research conducted based on the integration between Fuzzy logic algorithm and GIS techniques, spatial analysis tools in ArcGIS software were utilized to implement this method. The results showed that the most suitable areas include three areas that are located on the north-west and the south of the study area. On the other hand, the largest area located on the north-west location respect to Al-Hillah city, the center of Babylon Province, which is considered the proposed area to construct sports city. This study will be useful for decision-makers and stockholders by reducing cost, time, and efforts through decreasing field works.

\section{Introduction}

A sports activity is considered one of the main leisure activities in modern human's lives. Therefore, governments established several locations for various sports activities throughout the world. Nowadays, many governments have grouped new sports infrastructures in concentrated areas to create so-called sports cities [1]. In Iraq, Babil Province is considered one of the most important provinces in the center of Iraq, Due to the high population growth and urban expansion, the region of Iraq's center requires the development of sport infrastructures. The lack of appropriate planning for such infrastructures is catastrophic. Further, decision-makers do not consider the proper spatial distribution of public services such as sports infrastructure. Furthermore, little attention has considered sports land-use criteria and proper location that may reduce the optimal performance of these areas and leads to problems in the future. The recent development in urban planning, which represented by the development of multi-criteria decision making through spatial analysis techniques shows a feasibility in the spatial decision making process, spatial analysis techniques $[2,3,4]$ Therefore, the present study is conducted to utilize the spatial analysis techniques based on the integration of Artificial Intelligence Algorithms (Fuzzy logic algorithm) and geomatics techniques (Geographic Information System, Global Position System, and satellite images) to support the multi-criteria decision-making process and planning to determine the suitability of lands for establishing a sports city in a region mainly located within Babil Governorate with some parts from Karbala and Najaf Governorates. ArcGIS software includes several 
tools such as spatial analysis tools, which can perform multi-criteria decision-making to find suitable locations based on several parameters. In addition, ArcGIS includes the Fuzzy logic algorithm, which is a widely used method of site selection. It assigns membership values to locations that range from 0 to 1 (ESRI). 0 indicates non-membership or an unsuitable site, while 1 indicates membership or a suitable site. Without using traditional methods that manually assigning weights for criteria. Spatial analysis used in the present study can be used as a tool to support the multi-criteria decision-making processes in terms of suitable site selection in Iraq. The proposed method can be used to reduce fieldworks cost, time, and efforts.

\section{Related works}

Spatial analysis is an important tool for support decision making process $[5,6,7]$. Regarding the suitability analysis for finding suitable locations for establishing a sports city, many studies have been conducted, in this part we will describe the relevant studies. [8,9] developed model based on GIS and AHP to find suitable location for sport venue area in Tehran, Iran, the main drawback of AHP methods that requires a previous knowledge and weights for each criterion make it not usually suitable for suitability analysis. On the other hand, [10] proposed a methodology based on the Geographic Information System to detect suitable location for establishing a sports venue location, their study considered time consuming through the field investigation and creating analysis. In a separate study, [11] proposed a methodology based on Geographic Information System to evaluate the pattern of sport tourism locations in Lahijan, Iran based on environmental factors, their study neglected many factors such as the proximity to other locations making this study limited for finding suitable location for sport infrastructures. In another study, [12] proposed a methodology to find optimal site location for sports site by using Geographic Information System techniques. Their study didn't focus on sports city concept. [13] Proposed a model based on AHP method and GIS to plan for suitable sports spaces in Zanjan City, Iraq. On the other hand, [14] proposed a methodology based on GIS technique to find optimal location for stadium location in Wuhan, China. Their study focused only on the factors that affect stadium construction rather than sports city. In this study we will propose the integration between Fuzzy logic algorithm and Geomatic techniques that represented by spatial analysis tools to find suitable location for establishment of sports city in the center of Iraq.

\section{Methodology and data}

\subsection{Research area}

This research was carried out near Hillah city in Babylon province. In addition, the study area includes some parts from Karbala and Najaf provinces, Iraq (Figure 1). The selected area of study is located south of Baghdad city, It's geographically located at the intersection of ( $\left.44^{\circ} 10^{\prime} 0^{\prime} \mathrm{E}, 32^{\circ} 40^{\prime} 0^{\prime \prime} \mathrm{N}\right)$ and $\left(44^{\circ} 40^{\prime} 0^{\prime \prime} \mathrm{E}, 32^{\circ} 20^{\prime} 0^{\prime \prime}\right)$. The city of Hillah is considered as the center of the province of Babylon and it is $89 \mathrm{~km}$ to the south of Baghdad.

The total area of the study area is approximately $2797 \mathrm{~km}^{2}$ and has a population of about 2,065,042 people in 2018 . The study area is characterized by numerous land use locations such as commercial, industrial, residential areas and several human activities and infrastructures that recently increased. Moreover, there are many historical locations such as old Babylon city distributed near the city making this area attraction location for tourism (Figure 2). On the other hand, agricultural fields covered large areas in Babylon Province [15]. In addition, the weather in this area is considered cold in winter and hot-dry in summer.

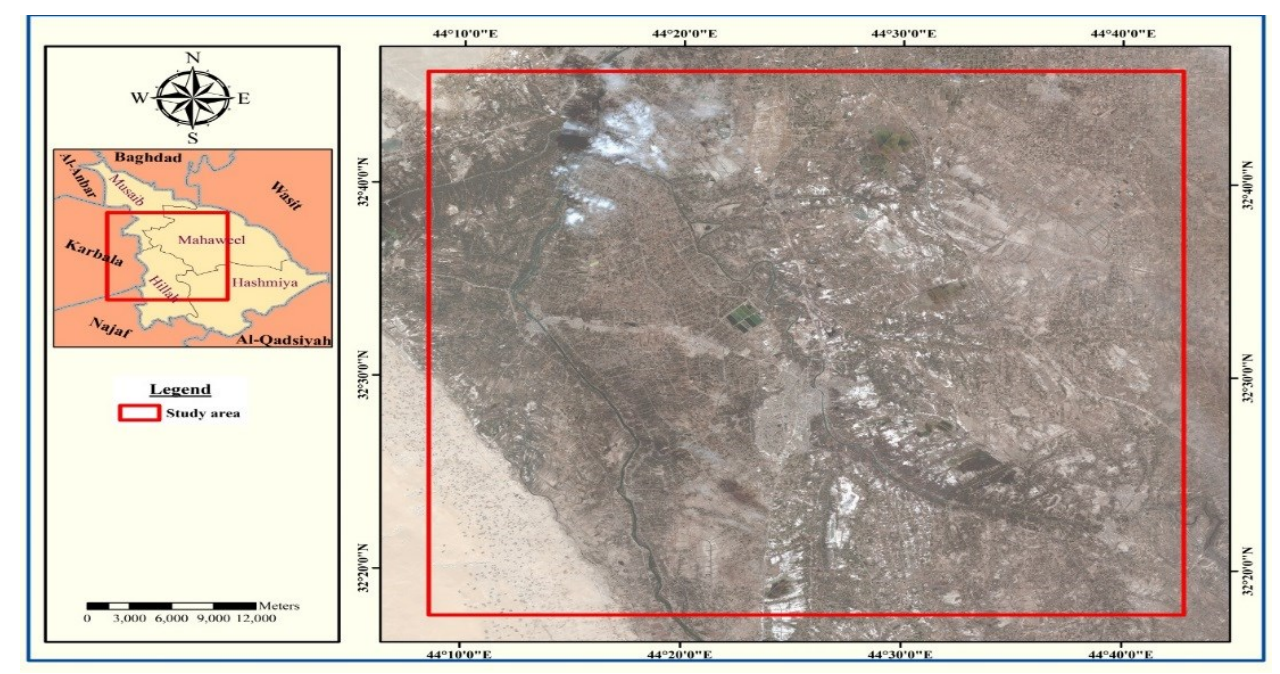

Figure 1: The study area. Source the author 


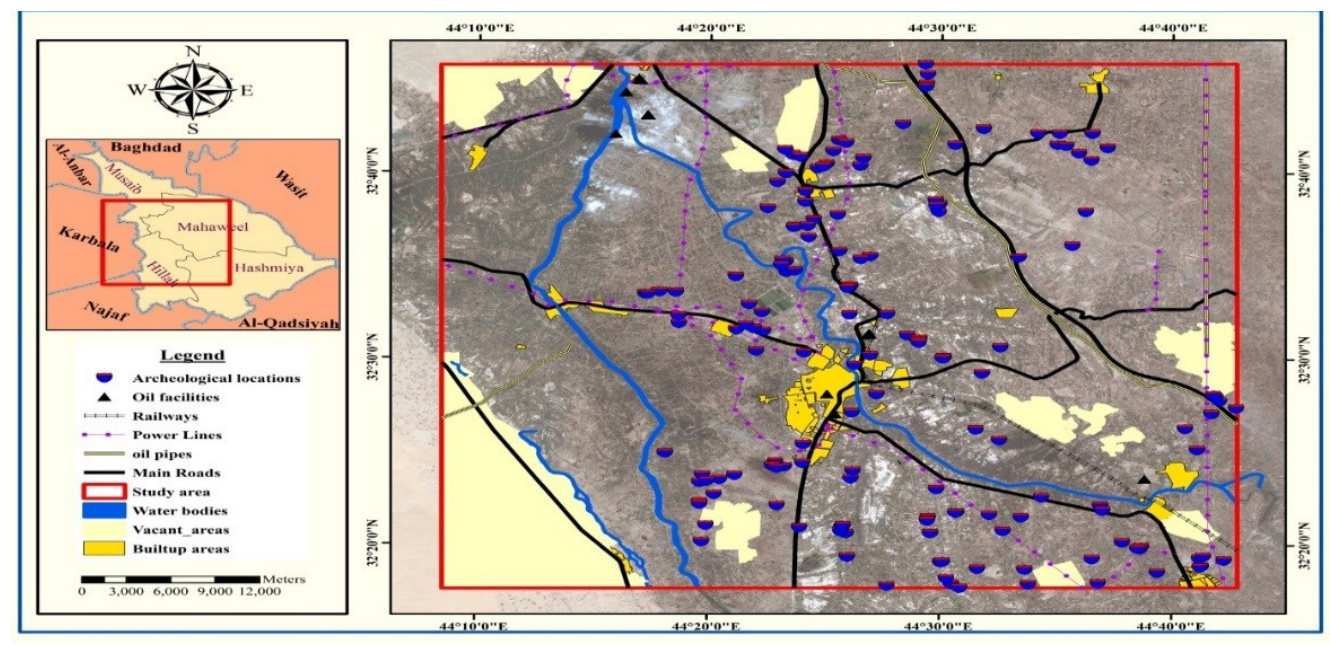

Figure 2: criteria used Source the author

\subsection{Suitability criteria}

In this study, we used eight criteria derived from different data sources in order to find suitable locations to establish a sports city. These criteria were collected from governmental data (i. e ministry of planning and the municipality of Babil Governorate. On the other hand, these criteria were prepared and organized in a GIS environment. These criteria were distance from archeological locations, distance from main roads, distance from railway, distance from oil pipes, distance from oil facilities, distance from power lines, distance from water bodies, distance from built-up areas as shown in table (1).

Table 1: The used criteria

\begin{tabular}{lcc}
\hline No. & data & Criterion \\
\hline 1 & archeological locations & as far away as possible from the game city \\
2 & main roads & as close as possible from the game city \\
3 & railway & as close as possible from the game city \\
4 & oil pipes & as far away as possible from the game city \\
5 & oil facilities & as far away as possible from the game city \\
6 & power lines & as far away as possible from the game city \\
7 & water bodies & as far away as possible from the game city \\
8 & built-up areas & as close as possible from the game city \\
\hline
\end{tabular}

\subsection{The Overall methodology}

The proposed methodology contains several steps, the first step is the data collected and preparing in GIS environment. Then, the criteria were created by using spatial analysis tools in ArcGIS software, the Euclidean distance analysis was used to calculate the distances from each criterion, where Euclidean Distance gives the distance from each cell in the raster to the closest source. Such as (Euclidean distance from archeological locations, Euclidean distance from main roads, Euclidean distance from railway, Euclidean distance from oil pipes, Euclidean distance from oil facilities, Euclidean distance from power lines, Euclidean distance from water bodies, Euclidean distance from built-up areas).

Then, we used the reclassification tool in ArcGIS to reclassify Euclidean distances were reclassified into specific ranks ranged from 1 to 10 , where rank 10 refers to the suitable values, and rank 1 refers to the unsuitable values. In this study we used Fuzzy logic algorithm, Fuzzy logic can be used as an overlay analysis technique to solve traditional overlay analysis applications such as site selection and suitability models. The basic premise behind fuzzy logic is that there are inaccuracies in attribute and in the geometry of spatial data. The proposed criteria were analyzed by using fuzzy membership. The Fuzzy Membership tool reclassifies or transforms the input data to a 0 to 1 scale based on the possibility of being a member of a specified set. 0 is assigned to those locations that are definitely not a member of the specified set, 1 is assigned to those values that are definitely a member of the specified set, and the entire range of possibilities between 0 and 1 are assigned to some level of possible membership (the larger the number, the greater the possibility).

The results of fuzzy membership were calculated by using fuzzy overlay and intersected with the vacant areas that obtained from governmental data in order to obtain suitability map. The final step included conversion of raster data to vector data to select final area based on the area. By using selection analysis, we selected the final proposed suitable location to establish sports city. The overall methodology is illustrated in Figure 3. 


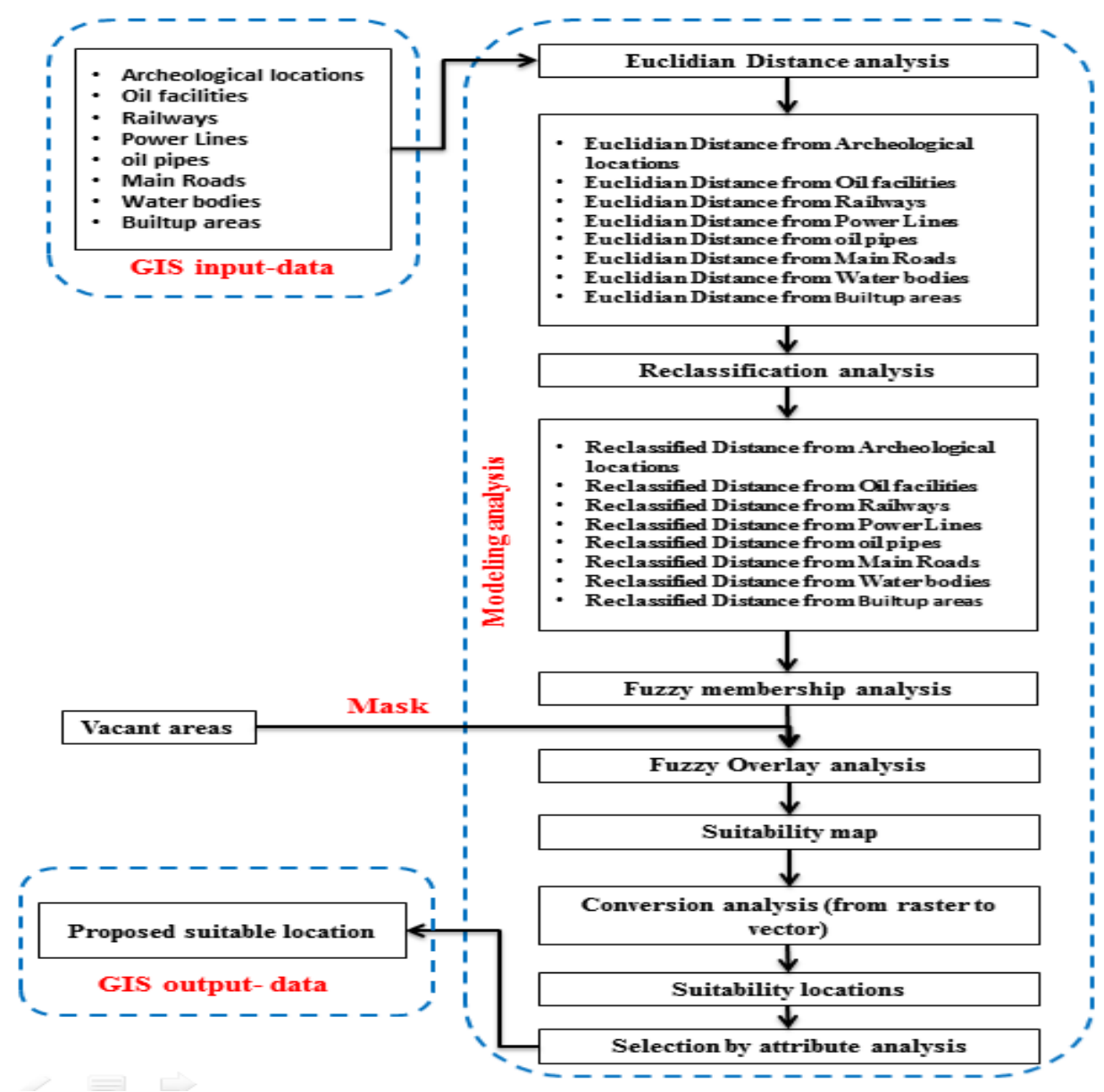

Figure 3: The proposed methodology

\section{The Suitability analysis}

\subsection{Spatial Analysis tools}

In this part, we describe the spatial analysis process, which was performed based on spatial analysis tools. We applied Euclidean distance analysis to calculate distances from each criterion. In general, "the Euclidean algorithm" works as follows: for each cell, the distance to each source cell is determined by calculating the hypotenuse with $\mathrm{x}_{-}$max and y_max as the other two legs of the triangle.

This calculation derives the true Euclidean distance, rather than the cell distance. The shortest distance to a source is determined, and if it is less than the specified maximum distance, the value is assigned to the cell location on the output raster".

In this research, we used the Euclidean distance tool that available in ArcGIS software, which can calculate Euclidean distances from multiple features within a single layer simultaneously and produce a single raster included the values of Euclidean distances. We calculated the Euclidean distance for eight criteria that input as shape files such as (Euclidean distance from archeological locations, Euclidean distance from main roads, Euclidean distance from railway, Euclidean distance from oil pipes, Euclidean distance from oil facilities, Euclidean distance from power lines, Euclidean distance from water bodies, Euclidean distance from built-up areas).Figure $(4,5)$.

After that, the Euclidean distances resulted were reclassified into specific ranks, The reclassification tools reclassify or change cell values to alternative values in order to simplify the information in a raster, Euclidean distances reclassified ranged between (1-10) in order to facilitate the analysis process. To perform this task, we utilized reclassify tools in ArcGIS (Figure $6,7)$. According to reclassify tools, we can modify values to ranks and save changes into new output. There are many purposes why we may want to apply reclassification such as changing values that relied on new information, grouping input data, reclassifying values to a specific scale, setting values to zero value. After that all criteria were subjected to overlay analysis based on spatial analysis tools in ArcGIS software. In this study, we applied Fuzzy overlay as the main algorithm for the overlaying process. On the other hand, we used vacant areas as a restricted parameter for the final suitable areas. 


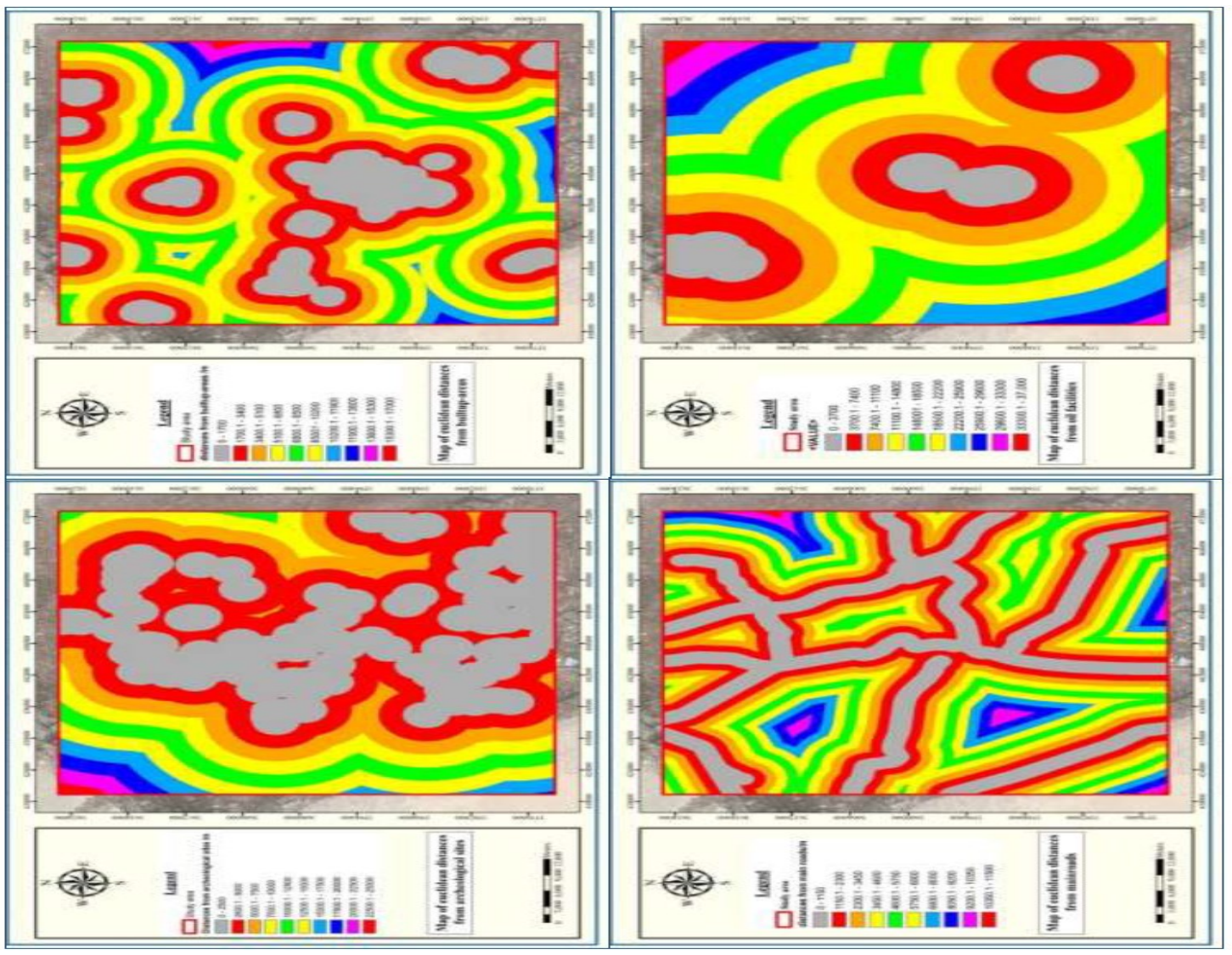

Figure 4: Euclidean distances from ( archaeological sites, built-up areas , oil facilities, and main roads)

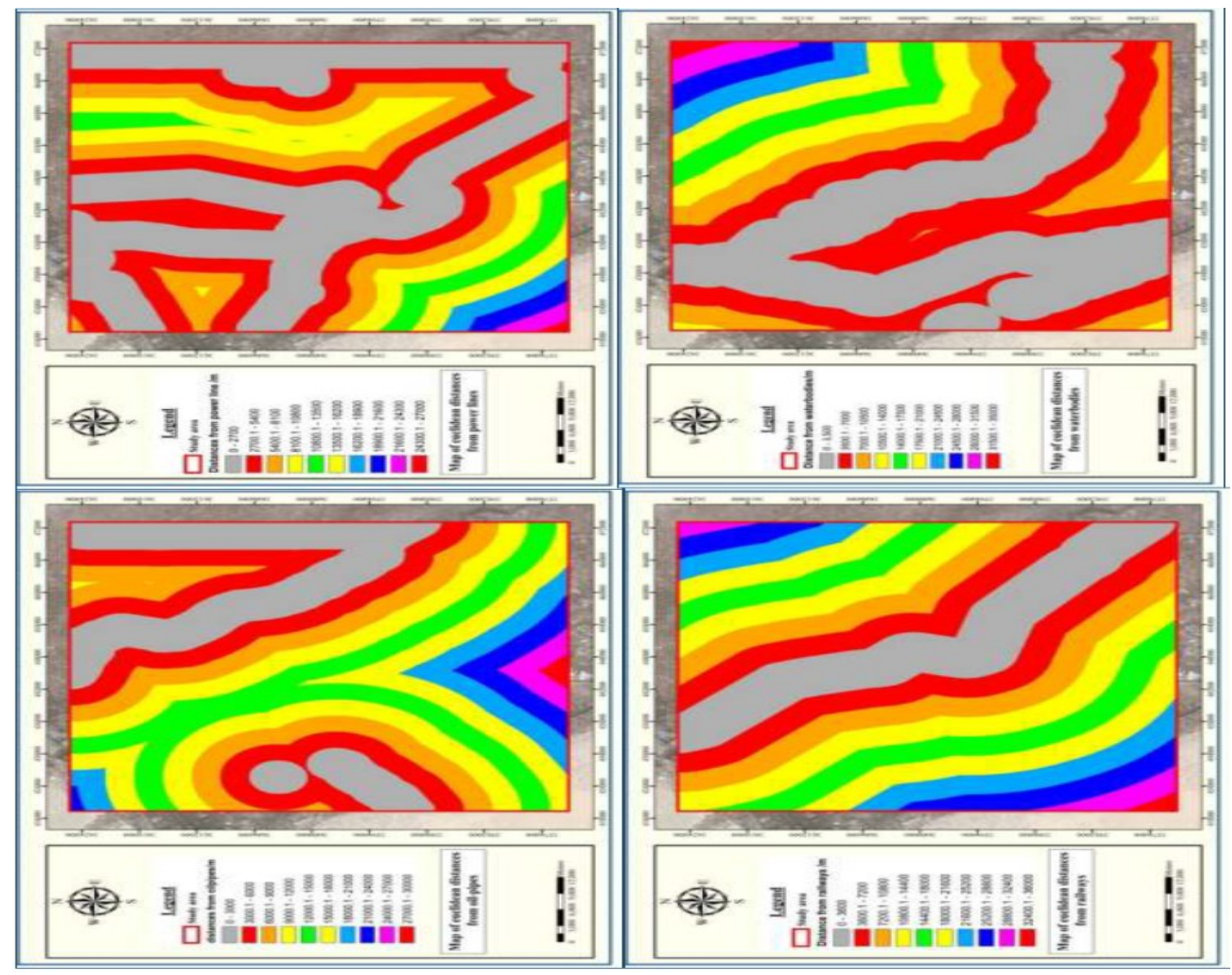

Figure 5: Euclidean distances from (oil-pipes, power lines, Railways, and Waterbodies) 


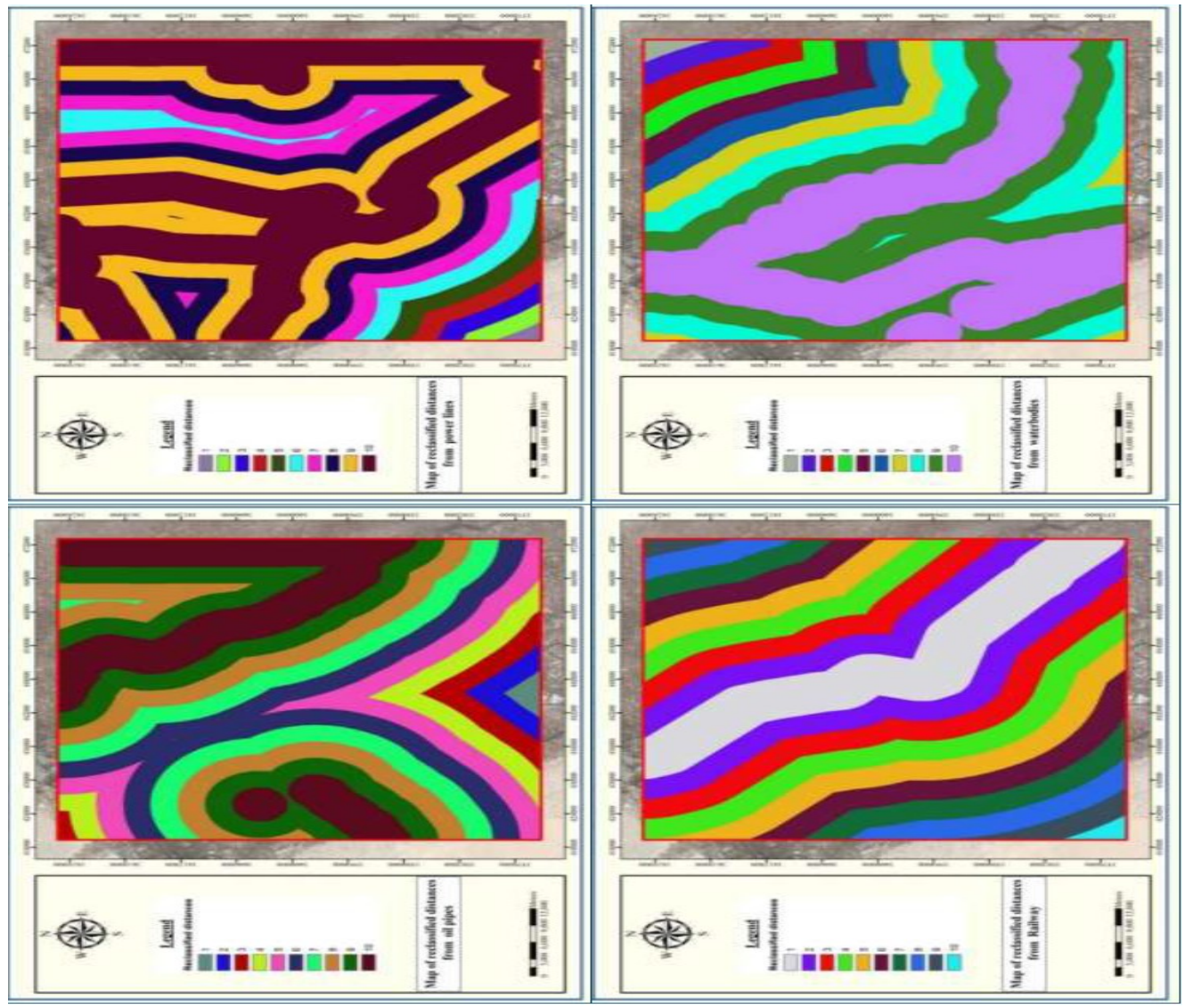

Figure 6: Reclassified distances from (archaeological sites, built-up areas, oil facilities, and main roads)

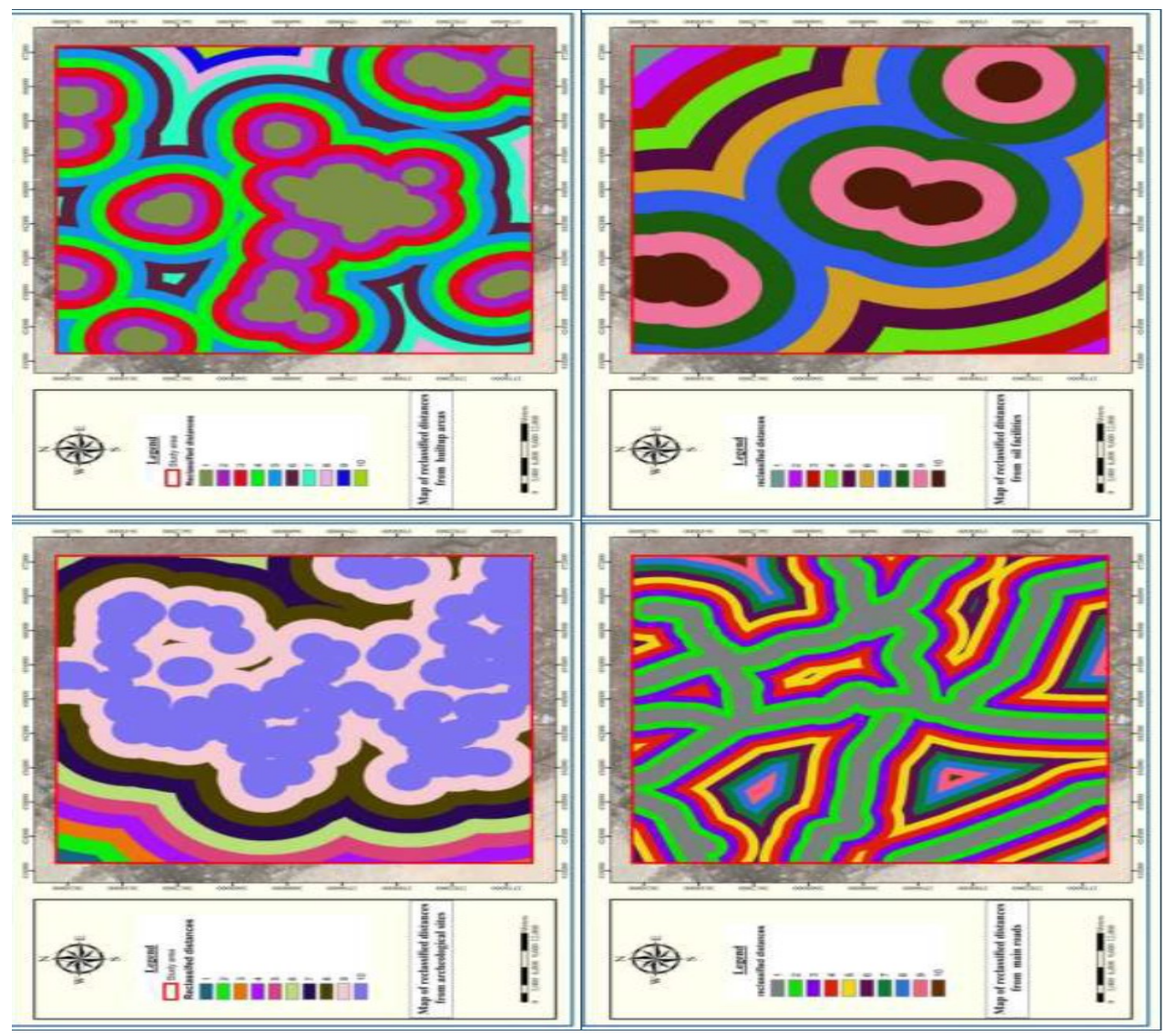

Figure 7: Reclassified distances from ( oil-pipes, power lines, Railways, and Water-bodies) 
Table 2: The optimal distances for each criteria and Ranks

\begin{tabular}{ccc}
\hline Criterion & Euclidean distance (m) & Rank \\
\hline Water bodies & $31500.1-35000$ & 1 \\
Main Roads & $0-1150$ & 1 \\
Railway & $0-3600$ & 1 \\
Power Lines & $0-2700$ & 1 \\
Oil pipes & $27000.1-30000$ & 1 \\
Oil facilities & $33300.1-37,000$ & 1 \\
Built-up areas & $0-1700$ & 1 \\
\hline Archeological locations & & 1 \\
\hline
\end{tabular}

\subsection{Fuzzy algorithm}

The fuzzy logic algorithms have been developed to model ambiguity in both attribute and geometry of geospatial data [16]. In terms of overlay analysis, fuzzy logic methods usually focus on ambiguity or inaccuracies in the semantic data (attributes). Generally, ambiguity occurs in two areas within attribute data (features definition, phenomena's measurement). These inaccuracies lead to errors during assigning cells to a specific class. Consequently, ambiguity can negatively impact decision-making operations. Thus, fuzzy overlay tools can help decision-making operations by modeling ambiguity in class boundaries [17].

Theoretically, fuzzy logic system is trying to work as close as human perception, which assumes that people not only thinking about definite variables (yes or no) but also thinking about "blurry" values like (maybe yes, maybe no). Therefore, fuzzy logic system capable of working with blurred boundaries and cloudy information [15]. Fuzzy logic overlay process is working by setting a membership value to the resulted locations ranged between 0 and 1 . Which 0 value refers to unsuitable or non-membership. While 1 value indicates a suitable site or membership [17]. In this study, we have used 8 parameters as input parameters ( i.e. Euclidean distance from archeological locations, Euclidean distance from main roads, Euclidean distance from railway, Euclidean distance from oil pipes, Euclidean distance from oil facilities, Euclidean distance from power lines, Euclidean distance from water bodies, Euclidean distance from built-up areas). The main reason to use Fuzzy overlay rather than other methods such as weighted overlay is the lack of criterion's weight that may obtained from previous knowledge or studies. On the other hand, fuzzy algorithm is presented as an analysis tool within ArcGIS software (spatial analysis tools in Fuzzy overlay tool) (Figure 8).

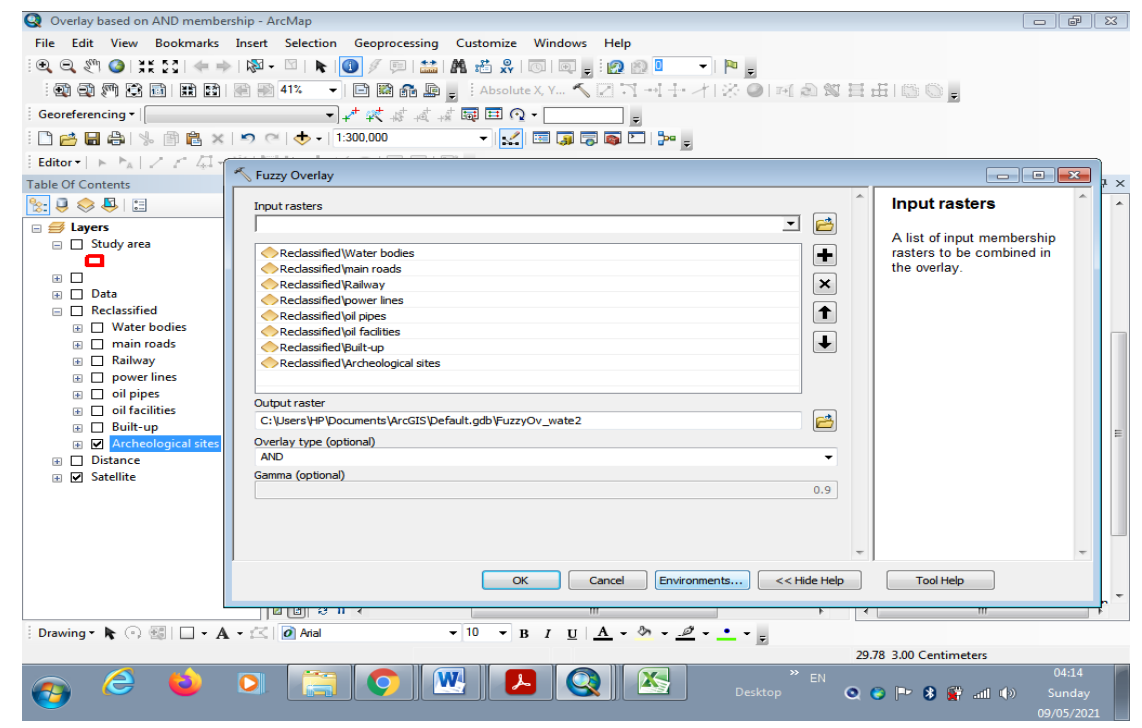

Figure 8: Fuzzy Overlay analysis.

\section{Results and Discussion}

\subsection{Results of fuzzy algorithm}

According to the result of fuzzy membership that considered the main step in the fuzzy overlay process, the membership values obtained from proposed criteria, where the highest membership value is 0.55 with water bodies criterion. While the lowest membership value is 0.002 with main roads. While other criteria are; Archeological locations 0.54 , Oil facilities 0.40 , Railways 0.27, Power Lines 0.003, oil pipes 0.45, Built-up areas 0.24.Figure 9 


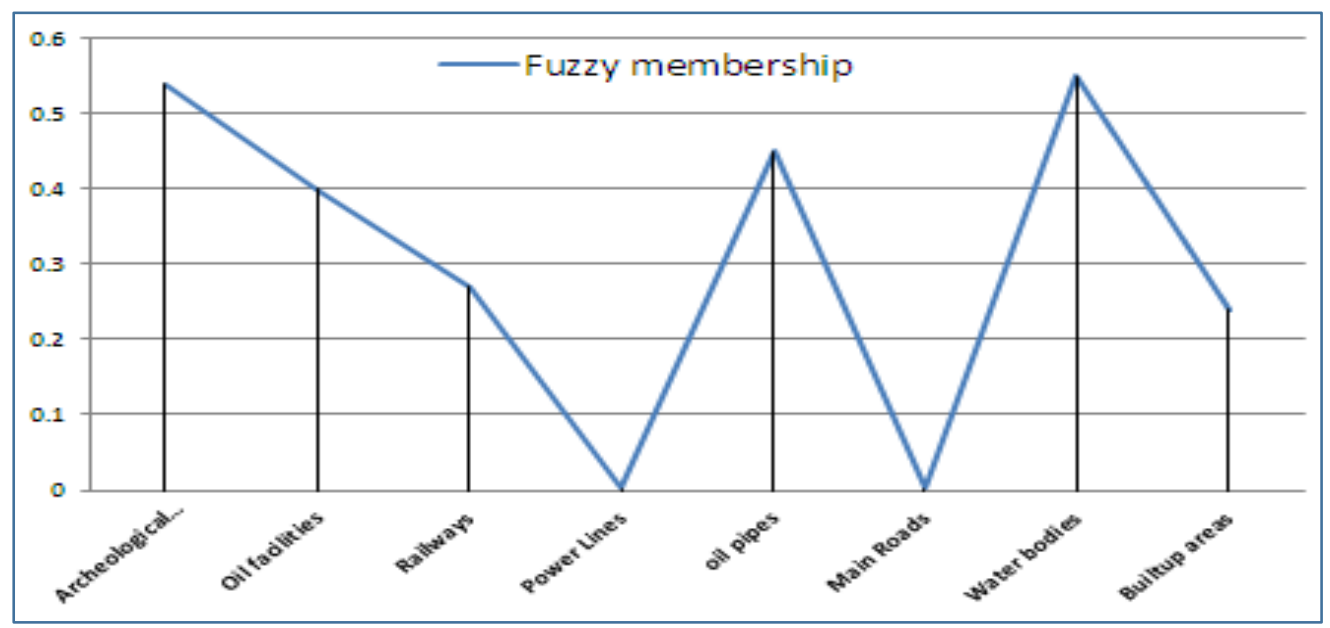

Figure 9: Fuzzy membership values

According to the suitability map showed in figure 11 that obtained from our methodology to find suitable locations for establishing sports city, five suitability classes have been resulted high suitable, Moderate suitable, low suitable, unsuitable, and High unsuitable. Fuzzy overlay values were calculated based on values resulted from fuzzy membership calculations, the highest fuzzy membership value ranged from 0.7 to 0.96 , Figure 10 shows the areas with Km2 unit that covered by each suitability class, where the high suitable covered approximately 5.79 , moderate suitable 56.84 , low suitable 62.94 , unsuitable 99.87, and high unsuitable 65.45.From the suitability maps we can conclude that the high suitable areas covered the least area in the study area. Consequently, this map can reduce the efforts, time, and cost of the field investigation. On the other hand, the high suitable areas are located on the north-west and the south of the study area. The high suitable area includes three areas. One of these areas has an area $5.35 \mathrm{~km} 2$ while other areas have areas less than $1 \mathrm{~km} 2$.After that we applied selection by attribute analysis in order to select area that suitable for establish sports city. The results showed that only one area that resulted which has the highest area $5.35 \mathrm{~km}^{2}$ (Figure 12), which is located on the north-west of the study area. Although our results selected suitable area for construct sports city, there still some investigations are required such as land price and cultural investigations. Our study showed that the integration between machine learning algorithms and Geomatics techniques are very useful to support the decision-making process in the site selection field. Figure 10 shows the final suitable location for establishing a sports city.

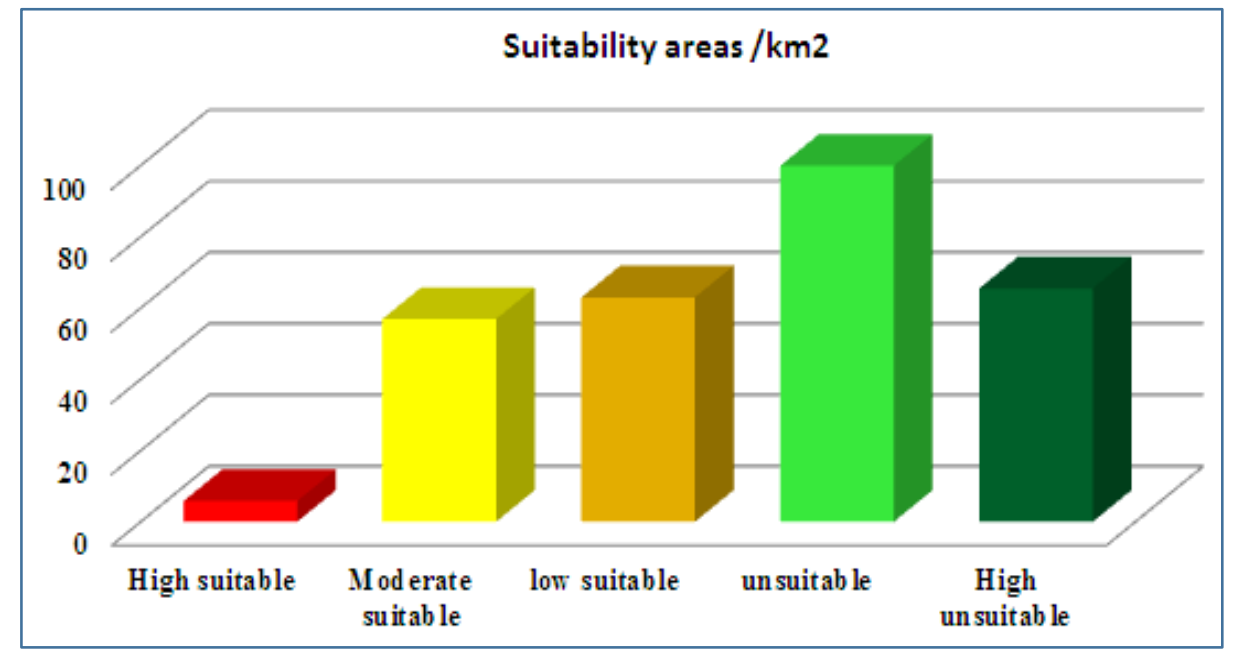

Figure 10: Areas of suitability classes 


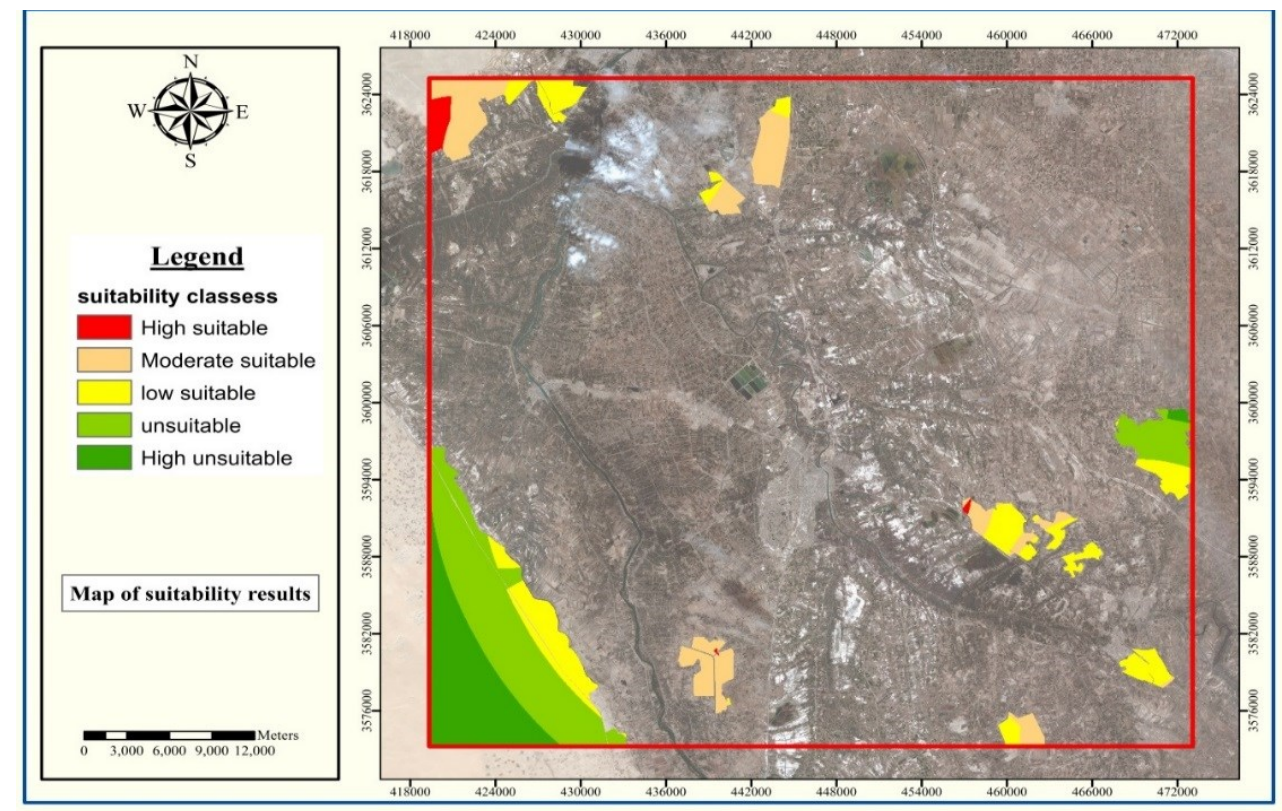

Figure 11: The suitability classes and locations

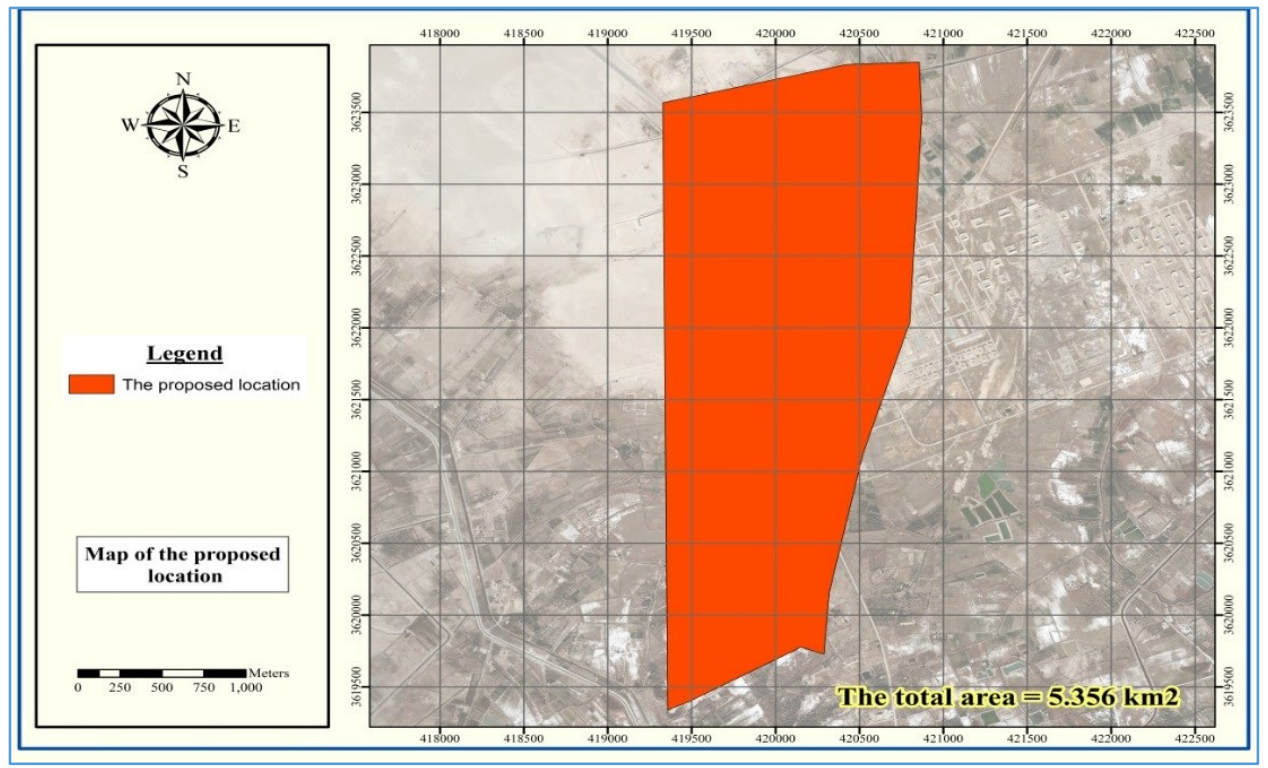

Figure 12: The proposed locations

\section{Conclusions}

Sport cities are considered as important infrastructures in urban environment in most cities in the world. Several methods were applied to perform suitability analysis. Recently, the geomatics techniques with machine learning algorithms have attracted scientists. Therefore, in this study we applied the integration between fuzzy logic algorithm and spatial analysis techniques to find suitable locations for establishing a sport city in the center of Iraq. In this study, we used 8 criteria as input data in the proposed methodology; Euclidean distance from archeological locations, Euclidean distance from main roads, Euclidean distance from railway, Euclidean distance from oil pipes, Euclidean distance from oil facilities, Euclidean distance from power lines, Euclidean distance from water bodies, Euclidean distance from built-up areas. The results showed that the high suitable areas include three areas that are located on the north-west and the south of the study area. On the other hand, the largest area located on the north-west location respect to Al-Hillah city, the center of Babylon Province, which is considered the proposed area to construct sports city. This study will be used as an efficient tool for decision-makers by the Iraqi Government by reducing cost, time, and efforts through minimizing the field works.

\section{Acknowledgements}

The authors acknowledge the logistic support of the ministry of municipalities in Iraq.

\section{Author Contribution}


All authors contributed equally to this work.

\section{Funding}

This research received no specific grant from any funding agency in the public, commercial, or not-for-profit sectors.

\section{Data Availability Statement}

The data that support the findings of this study are available on request from the corresponding author.

\section{Conflicts of Interest}

The authors declare that there is no conflict of interest.

\section{References}

[1] A.Smith,(2010). The development of "sports-city zones and their potential value as tourism resources for urban areas". European Planning Studies, 18(3), 385-410.

[2] O. Z.Jasim, Hassoon, K. I., \& Sadiqe, N. E. (2019). “Mapping LCLU Using Python Scripting“"Engineering andTechnology Journal, 37(4A), 140-147.

[3] N. H.Hamed, M. M.Bayati, \& H.R.Mohammed, (2020), "Digital Change Detection and Map Analysis for UrbanExpansion and Land Cover Changes in Karbala City" ,Engineering and Technology Journal, 38(9A), 1246-1256.

[4] T. H.Shihab, A. N.Al-Hameedawi, A. M.Hamza, (2020).” Random Forest (RF) and Artificial Neural Network (ANN) Algorithms for LULC Mapping”, Engineering and Technology Journal, 38(4A), 510-514.

[5] H.R.Mohammed, N. H.Hamed,M. M.Bayati, (2018). "Building of a Spatial Database to Identify Areas of Contamination by Mines and Hazardous Remnants of War by Using GIS (Analyti-cal Study/Basra Governorate)". Anbar Journal of Engineering Sciences, 7(3), 252-259.

[6] A.Al-Hameedawi, M.Salih, H.R.Mohammed, M.Hassan, (2018)." Selecting optimum railway track using GIS techniques", In MATEC Web of Conferences (Vol. 162, p. 03018). EDP Sciences.

[7] N. H.Hamed,M. M.Bayati, H.R.Mohammed, (2020).’Digital Change Detection and Map Analysis for Urban Expansion and Land Cover Changes in Karbala City", Engineering and Technology Journal, 38(9A), 1246-1256.

[8] H.R. Mohammed ( $(\cdot \cdot \cdot)$," Mapping Paddy Rice Fields Using Landsat and Sentinel Radar Images in Urban Areas for Agriculture Planning“,Journal of planner and development, (41), 1-28.

[9] M.Namvar, \& M. H.Razavi, (2016),"Spatial distribution and location of sports venues using AHP model and GIS techniques (Case Study: Tehran)".

[10] M. H., S. M., and M. J.Jolandan. "Locating Sports Facilities in City of Talesh by Using AHP in the GIS Environment."

[11] M.Tavakkoli, \& E.Dehghani, Sport Tourism Site Selection Model by Environmental Capability Evaluation: Lahijan County.

[12] O.Jamshidi, M.Doostipasha,, S. M. H., M.Gudarzi, (2018),"Adjustment of optimal sports site selection criteria for elderly using analytical hierarchy process and geographic information system". Iranian Journal of Ageing, 12(4), $506-517$.

[13] G. H.Fazelniya, A.Kiani, M.Rastegar, (2010),’OPTIMUM SITE SELECTION SPACES SPORTS ZANJAN USING ANALYTICAL IERARCHY PROCESS (AHP) MODEL AND GEOGRAPHIC INFORMATION SYSTEM (GIS).

[14] L. X. PENG, \& GUO, W. Y.GUO, (2011)," The Research on Best Site Selection of Stadium in A City Based on GIS". Journal of Wuhan Institute of Shipbuilding Technology, 1.

[15] A.Chabuk, N.Al-Ansari, H. M.Hussain, (2017). Combining GIS Applications and Method of Multi-Criteria DecisionMaking (AHP) for Landfill Siting in Al-Hashimiyah Qadhaa, Babylon, Iraq. Sustainability, 9(11), 1932.

[16] K. H.Chi, N. W.Park, C. J.Chung, (2002). "Fuzzy logic integration for landslide hazard mapping using spatial data from Boeun, Korea",. International archives of photogrammetry remote sensing and spatial information sciences, 34(4), 54-59.

[17] G.Klir, B.Yuan, (1995),'Fuzzy sets and fuzzy logic”, (Vol. 4). New Jersey: Prentice hall.

[18] K.Valaskova, T.Kliestik, M.Misankova," The role of fuzzy logic in decision making process", Management innovation and business: 2nd international conference on Management innovation and business, Thailand, 2014 (pp. 143-148). ISBN 978-981-09-1685-5. 